Correction

\title{
Correction: Deuchar, Margaret. 2020. Code-Switching in Linguistics: A Position Paper. Languages 5: 22
}

\section{Margaret Deuchar}

Theoretical and Applied Linguistics, University of Cambridge, Cambridge CB2 1TN, UK; m.deuchar@gmail.com Received: 17 December 2020; Accepted: 17 December 2020; Published: 21 December 2020

The author wishes to make the following correction to the paper by Deuchar (2020).

Figure 5 (p. 8):

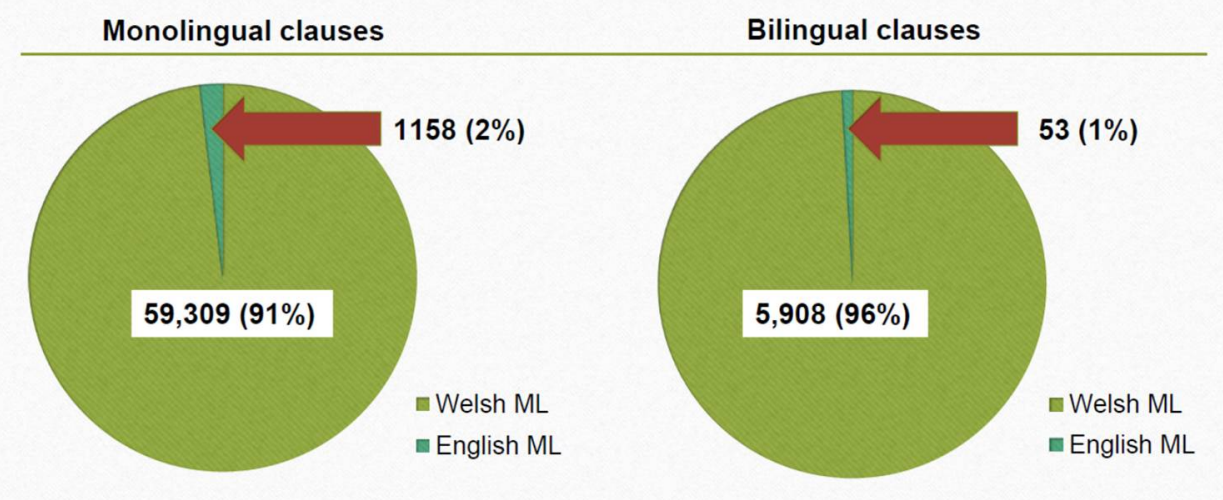

Figure 5. Quantitative distribution of matrix language in Siarad corpus.

should be replaced by:

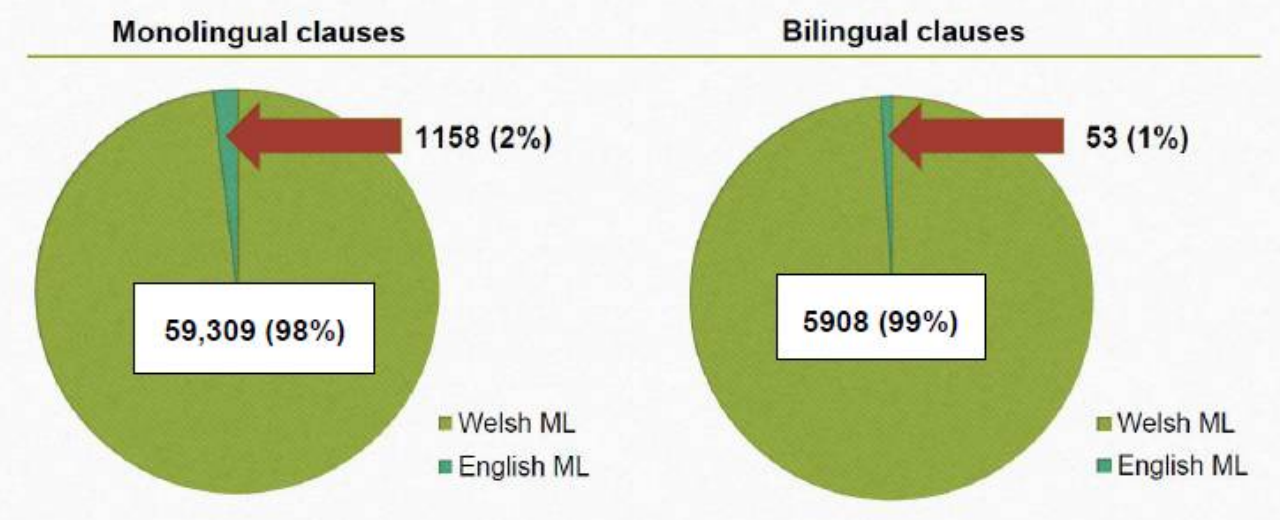

Figure 5. Quantitative distribution of matrix language in Siarad corpus.

These changes have no material impact on the conclusions of the paper. The authors would like to apologize for any inconvenience caused to the readers by these changes. 


\section{Reference}

Deuchar, Margaret. 2020. Code-Switching in Linguistics: A Position Paper. Languages 5: 22. [CrossRef]

Publisher's Note: MDPI stays neutral with regard to jurisdictional claims in published maps and institutional affiliations.

(C) 2020 by the author. Licensee MDPI, Basel, Switzerland. This article is an open access article distributed under the terms and conditions of the Creative Commons Attribution (CC BY) license (http://creativecommons.org/licenses/by/4.0/). 